\title{
28 Research Square \\ High prevalence of intrathecal IgA synthesis in multiple sclerosis patients
}

\author{
Ursula Muñoz \\ CEU San Pablo University \\ Cristina Sebal \\ CEU San Pablo University \\ Esther Escudero \\ CEU San Pablo University \\ Maria Isabel García Sánchez \\ Hospital Universitario Virgen Macarena \\ Elena Urcelay \\ Hospital Clínico San Carlos \\ Asier Jayo \\ CEU San Pablo University \\ Rafael Arroyo \\ Hospital Universitario Quirónsalud Madrid \\ Maria A García-Martínez \\ Hospital Clínico San Carlos \\ Roberto Álvarez-Lafuente \\ Hospital Clínico San Carlos \\ María C Sádaba ( $\nabla$ mariacruz.sadabaargaiz@ceu.es ) \\ CEU San Pablo University
}

\section{Research Article}

Keywords: multiple sclerosis, oligoclonal bands, isoelectrofocusing, intrathecal IgA synthesis

Posted Date: September 21st, 2021

DOI: https://doi.org/10.21203/rs.3.rs-892637/v1

License: (c) (i) This work is licensed under a Creative Commons Attribution 4.0 International License. Read Full License

Version of Record: A version of this preprint was published at Scientific Reports on March 11th, 2022. See the published version at https://doi.org/10.1038/s41598-022-08099-y. 


\section{Abstract}

Introduction: The detection of intrathecal IgA synthesis (IAS) in multiple sclerosis (MS) is cumbersome, for this reason, we developed a highly sensitive assay to assess it in MS.

Methods: $151 \mathrm{MS}$ patients and 22 controls with different neurological diseases were recruited. IgA concentration was analyzed by ELISA. Oligoclonal IgA bands to detect IAS were determined by a new ultrasensitive assay based on isoelectrofocusing (IEF).

Results: Most individuals showed an IgA concentration within normal range in serum samples (95.95\%) but $38.41 \%$ of individuals had a low IgA concentration in the cerebrospinal fluid (CSF), with no significant differences observed between MS and control groups, neither in CSF nor in serum. The new IEF was more sensitive than those previously described $(0.01 \mathrm{mg} / \mathrm{dl}$ of $\lg \mathrm{A})$, and clearly identified patients with and without IAS, that was not related with $\lg A$ concentration. MS patients showed higher percentage of IAS (43.00\%) than the control group $(18.20)(p=0.035)$, because the incidence was especially higher in MS patients with clinically isolated syndrome (CIS, 66.00\%).

Conclusions: Intrathecal IgA synthesis is observed more frequently in MS patients than in other neurological diseases, and with higher incidence than assumed in the past.

\section{Introduction}

The detection of intrathecal (cerebrospinal fluid, CSF) synthesis of $\lg \mathrm{G}^{1-3}$ and $\lg \mathrm{M}^{4,5}$ are hallmarks for the diagnosis and prognosis of multiple sclerosis (MS) patients. Intrathecal synthesis of these immunoglobulins is detected using quantitative and qualitative methods. The latter, based on the identification of oligoclonal bands in CSF vs. paired serum, is more sensitive than the former ${ }^{6}$.

In contrast, there are not many reports about the role of IgA in MS patients. Quantitative analysis of the CSF demonstrated that $18 \%$ of patients present intrathecal IgA synthesis (IAS), ${ }^{7}$ and qualitative analysis of these samples showed similar results ${ }^{8}$. At present, the detection of $\lg A$ in MS patients is not used in clinical routine. Nevertheless, in the central nervous system (CNS) of MS patients, IgA-positive plasma cells were claimed to be the main source of IgA deposits along axons detected in the lesions, which in turn, were related with axonal damage ${ }^{9}$. Moreover, IgA-positive lymphocytes have been detected in the CSF from MS patients ${ }^{10}$. Additionally, the presence of virus in the CNS ${ }^{11}$, and of antibodies against these pathogens, were described in over $90 \%$ of CSF samples from MS patients ${ }^{7}$. Therefore, we reasoned that the detection of IgA in CSF from MS patients might be underestimated. In CSF, both the very low IgA concentration, ${ }^{12}$ and being a highly glycosylated dimeric immunoglobulin, hamper the establishment of quantitative and qualitative analyses.

We aimed to develop an ultrasensitive and specific assay for the detection of IgA oligoclonal bands (OGIgAB) in CSF and serum samples in order to study the intrathecal IgA synthesis in MS patients.

MATERIALS AND METHODS

\subsection{Samples}

Samples were obtained from, Hospital Clínico San Carlos, Hospital Universitario Quirónsalud (Madrid) and Biobanco del Hospital Universitario Virgen Macarena. Biobanco del Sistema Sanitario Público de Andalucía 
(B.B.S.S.P.A.).

We analyzed serum and CSF paired samples from 151 MS patients and 22 controls, which included 12 individuals with non-demyelinating neurological diseases (NDND) and 10 patients with non-MS demyelinating neurological diseases (NonMSDND)NDND comprised individuals suffering headache (2), amyotrophic lateral sclerosis (1), epilepsy (1), schizophrenia (1), cranial hypertension (2), No-Hodgkin Lymphoma (1), lymphocytic meningitis (1), meningococcal meningitis (1), myelopathy autoimmune (1), tumoral myelopathy (1), cerebellar syndrome (1), and capillary telangiectasia (1). NonMSDND included patients with myelitis (4), optic neuropathy (2), and polyneuropathy (2). All specimens were collected for clinical purposes, and the remaining material was stored at $-80^{\circ} \mathrm{C}$ until experiments were performed. The demographic and clinical data of all individuals are summarized in Table 1. 
Table 1

Demographic and clinical data from patients with MS, Non-MSMYD and Non-MYND

\begin{tabular}{|c|c|c|c|c|c|c|c|}
\hline Disease & & & FEMALES & AGE & $\begin{array}{l}\text { DISEASE } \\
\text { DURATION }\end{array}$ & $\begin{array}{l}\text { EDSS } \\
\text { SCORE }\end{array}$ & TREATMENT \\
\hline \multirow[t]{5}{*}{ MS (151) } & & & $\begin{array}{l}64.9 \% \\
(98)\end{array}$ & $\begin{array}{l}40.0 \\
(13- \\
80)\end{array}$ & $9.9(0-41)$ & $\begin{array}{l}3.5(0- \\
8.5)\end{array}$ & $17.9 \%(27)$ \\
\hline & CIS (56) & & $\begin{array}{l}67.9 \% \\
(38)\end{array}$ & $\begin{array}{l}34.89 \\
(13- \\
60)\end{array}$ & $2.9(0-13)$ & $\begin{array}{l}1.7(0- \\
6.5)\end{array}$ & $0 \%(56)$ \\
\hline & $\begin{array}{l}\text { RRMS } \\
(50)\end{array}$ & & $\begin{array}{l}60.0 \% \\
(30)\end{array}$ & $\begin{array}{l}38.1 \\
(18- \\
56)\end{array}$ & $8.9(0-28)$ & $\begin{array}{l}1.8(0- \\
4.5)\end{array}$ & $30 \%(15)$ \\
\hline & $\begin{array}{l}\text { SPMS } \\
(24)\end{array}$ & & $\begin{array}{l}70.8 \% \\
(17)\end{array}$ & $\begin{array}{l}45.8 \\
(29- \\
67)\end{array}$ & $\begin{array}{l}27.1(15- \\
41)\end{array}$ & $\begin{array}{l}6.1 \\
(3.5- \\
8.5)\end{array}$ & $33.3 \%(8)$ \\
\hline & $\begin{array}{l}\text { PPMS } \\
(21)\end{array}$ & & $\begin{array}{l}61.9 \% \\
(13)\end{array}$ & $\begin{array}{l}51.7 \\
(33- \\
80)\end{array}$ & $\begin{array}{l}11.6(1- \\
35)\end{array}$ & $\begin{array}{l}4.9 \\
(2.5- \\
7.5)\end{array}$ & $19 \%(4)$ \\
\hline \multicolumn{8}{|c|}{ CONTROLS } \\
\hline & $\begin{array}{l}\text { NON- } \\
\text { MSMYD } \\
(10)\end{array}$ & & $4(40.0 \%)$ & $\begin{array}{l}41.5 \\
(25- \\
59)\end{array}$ & & & \\
\hline \multicolumn{8}{|c|}{ Myelitis (4) } \\
\hline \multicolumn{8}{|c|}{ Polyneuropathy (2) } \\
\hline \multicolumn{8}{|c|}{ Optic neuritis (2) } \\
\hline & & \multicolumn{6}{|l|}{$\begin{array}{l}\text { Autoimmune } \\
\text { myelopathy (1) }\end{array}$} \\
\hline & & \multicolumn{6}{|l|}{$\begin{array}{l}\text { Secondary } \\
\text { myelopathy to tumor } \\
\text { (1) }\end{array}$} \\
\hline & $\begin{array}{l}\text { NON- } \\
\text { MYND } \\
(12)\end{array}$ & & $9(75.0 \%)$ & $\begin{array}{l}37.4 \\
(2- \\
72)\end{array}$ & & & \\
\hline \multicolumn{8}{|c|}{ Cephalea (2) } \\
\hline & & \multicolumn{6}{|l|}{$\begin{array}{l}\text { amiotrophyc lateral } \\
\text { sclerosis (1) }\end{array}$} \\
\hline & & \multicolumn{6}{|l|}{ Epilepsy (1) } \\
\hline & & Schizophrenia (1) & & & & & \\
\hline
\end{tabular}

MS: multiple sclerosis; CIS: clinically isolated syndrome; RRMS: relapsing-remiting multiple sclerosis; SPMS: secondary progressive multiple sclerosis; PPMS: primary progressive multiple sclerosis; Non-MSMY: non-MS myelin diseases; Non-MYND: nonmyelin neurologic diseases; Females and treatment: percentage and total number; Age, disease duration and EDSS score: mean (minimum and maximum. Patients were treated with Natalizumab (8), fingolimod (3), interferon- $\beta$ (8), Copaxone® (1), dimethyl fumarate (1) and 8 cases were included in a clinical trial. 


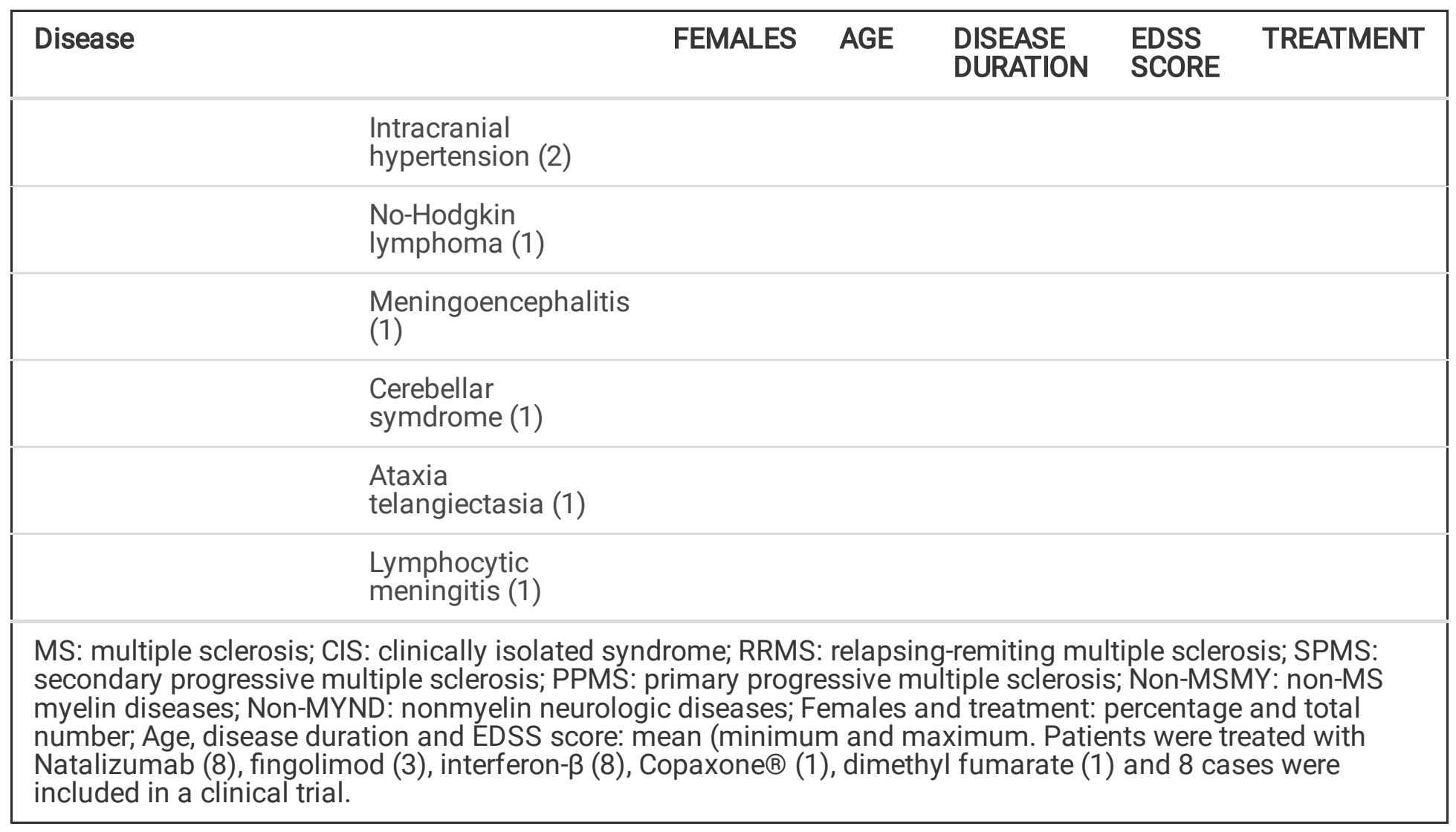

All methods were caried out in accordance with relevant guidelines and regulations.

All the protocols were approved by Committee of Bioethics of Hospital Clínico Universitario, Comittee of Biotethics of Hospital Universitario Quirónsalud and Committee of Investigación Biomédica de la Junta de Andalucía.

The informed consent was obtained from all the patients and/or their legal guardian(s). (As participants less than 16 years are also included).

Analysis of IgA concentration in CSF and serum samples by ELISA assay

We developed a quantitative assay to measure IgA concentrations in serum and CSF samples. Briefly, $400 \mathrm{ng}$ of anti-human IgA (Jackson ImmunoResearch) diluted in $100 \mu \mathrm{L}$ of phosphate buffered saline solution (PBS, Sigma) were added to every well of the microtiter plate (Greiner). After overnight incubation at $4^{\circ} \mathrm{C}$, the plates were washed and blocked with $200 \mu \mathrm{L}$ of bovine albumin (Sigma) diluted at $3 \%$ in PBS. To perform the standard curve, we added to the first row 2-fold serial dilutions (from $40 \mathrm{ng} / \mathrm{mL}$ to $0.08 \mathrm{ng} / \mathrm{mL}$ ) of IgA (NProtein Standard SL, Siemens). Then, 2-fold serial diluted samples (from 1:200 to 1:1600) were added to the wells. After overnight incubation, $100 \mu \mathrm{L}$ of biotinylated anti-human IgA (Jackson ImmunoResearch) diluted (1:10000) in blocking solution was added to the plates and incubated for 2 hours. Next, we added $100 \mu \mathrm{L}$ of streptavidin-HRP (horseradish peroxidase, Jackson ImmunoResearch) diluted (1:1000) in blocking solution. After 30 minutes incubation, color was developed using TMBone (Thermofisher) substrate. Finally, the reaction was stopped using $100 \mu \mathrm{L}$ of $\mathrm{H}_{2} \mathrm{SO}_{4}$ (Sigma Aldrich) diluted at $5 \%$ in distilled water, and plates were read in the Varioscan instrument (Thermofisher). Graphpad Prism v8 software was used to obtain all he standard curves and to calculate the IgA concentration in all samples analyzed.

In order to validate the ELISA, we analyzed the results of 15 ELISAs. To assess the linearity, the limit of blank (LoB, mean_blank $+1.645^{\star}$ SD_blank (standard deviation)) and reproducibility of the ELISA, we analyzed the absorbances 
of the standard curves and the blank rows. The absorbances obtained at IgA concentrations as low as 0.3125 $\mathrm{ng} / \mathrm{ml}$ were analyzed to obtain the limit of detection ( $\mathrm{LoB}+1,645^{\star} \mathrm{SD} \_l o w$ concentration samples). To study the coefficient of variation of the ELISA we analyzed the IgA concentration obtained using a control (N/T Protein Control SL, Siemens) at 2-fold dilutions (from $20 \mathrm{ng} / \mathrm{mL}$ to $0.08 \mathrm{ng} / \mathrm{mL}$ ) (Supplementary Data 1).

\subsection{Reiber index}

Serum and CSF albumin were analyzed in a Beckman-Coulter AU5400 instrument (Beckman Coulter), using the Olympus Albumin Reagent Test (Beckman Coulter) and the Urine CSF Album KIT (Beckman Coulter) when serum and CSF samples were analyzed respectively.

Software by Laboratory Enders \& Partners (www.labor-enders.de/19.html?\&L=1) was used to calculate Reiber index.

1.3 Isoelectrofocusing (IEF) and immunodetection assay for the detection of oligoclonal IgA bands in CSF and serum samples.

The protocol used was similar to described previously [1] but we introduced the modifications described below.

We incubated $40 \mu \mathrm{l}$ of CSF and serum samples with $5 \mu \mathrm{l}$ of $0.5 \mathrm{M}$ dithiothreitol and $5 \mu \mathrm{L}$ of $1 \mathrm{M} \mathrm{Tris} / \mathrm{HCl} \mathrm{pH}=9.7$, during 45 minutes.

For protein separation, we used an agarose gel consisting of $0.3 \mathrm{~g}$ of agarose (GE Healthcare); $3.6 \mathrm{~g}$ of sorbitol (Sigma-Aldrich); $1.25 \mathrm{~mL}$ of each Pharmalyte, $\mathrm{pH}$ 4-6.5 and $\mathrm{pH} 3-10$ (GE Healthcare); $2.5 \mathrm{~mL}$ of glycerol, and 22.5 $\mathrm{mL}$ of water.

To detect IgA, we used a biotinylated anti-human IgA antibody (Jakson Immunoresearch) diluted (1:20.000) in the blocking solution. After incubating the membrane overnight at $4^{\circ} \mathrm{C}$, the labeling was developed using streptavidinHRP (Jakson Immunoresearch) diluted (1:1.000) in blocking solution.

To study the sensitivity of this new assay (IEF and immunodetection), we analyzed paired CSF and serum samples from $3 \mathrm{MS}$ patients showing OGIgAB. We applied $5 \mu \mathrm{L}$ of 2 -fold serial diluted samples (from 2 to $0 \mathrm{ng}$ of $\mathrm{IgA}$ ) on the gel in triplicate.

To assay the limit of blank and the limit of detection, diluted CSF and serum samples with an extremely low quantity of IgA ( $0 \mathrm{ng}$ and $0.25 \mathrm{ng}$ respectively) were analysed.

\subsection{Image processing}

ImageJ1 (ImageJ, U. S. National Institutes of Health, Bethesda, Maryland, USA) was used to manage the images, and to quantify the staining signal in order to validate the OGIgAB pattern. Three measurements were obtained from every sample.

\subsection{Statistics}

IBM SPSS v24.0 software was used to analyze the data obtained. In order to analyze the linearity of both assays, ELISA and IEF and immunodetection, spearman test was used to analyze respectively the correlation between IgA concentration and absorbance or IgA concentration and relative optic density (O.D). In addition, linear regression was performed to study the distribution of the residuals and the collinearity of the data. Linearity of the assay was 
accepted when variance inflation factor $(\mathrm{VIF})<20$. The coefficient of variation represents the percentage of the standard deviation divided by the mean. To analyze the IgA concentration in CSF and serum samples MannWhitney U test was used to compare MS and control patients, and Kruskal-Wallis for comparisons among different MS types. To analyze the fraction of individuals harboring intrathecal IgA synthesis (IAS), we used the Fisher test for comparisons between MS and control group and the Pearson $\chi 2$ test for comparisons among different MS types. Statistical significant differences were accounted when $p<0.05$.

\section{Results}

\subsection{Analysis of the IgA concentration in CSF and serum samples by ELISA assay. Reiber diagram.}

Once validated the ELISA developed in our lab (Supplementary S1, Suplementary Fig. 1), we analyzed the samples from MS patients and control group. The IgA concentration in CSF and serum samples is summarized in Table 2.

Table 2

Analysis by ELISA of the IgA concentration in CSF and serum samples from MS patients and control groups.

\begin{tabular}{|c|c|c|c|c|c|c|c|c|}
\hline & & NonMSDND & NDND & MS & $\mathrm{CIS}$ & RR & SP & PP \\
\hline & & $(n=10)$ & $(n=12)$ & $\begin{array}{l}(\mathrm{n}= \\
151)\end{array}$ & $\begin{array}{l}(n= \\
56)\end{array}$ & $\begin{array}{l}(n= \\
50)\end{array}$ & $\begin{array}{l}(n= \\
24)\end{array}$ & $\begin{array}{l}(\mathrm{n}= \\
21)\end{array}$ \\
\hline \multirow[t]{3}{*}{$\begin{array}{l}\text { Serum IgA } \\
(\mathrm{mg} / \mathrm{dL})\end{array}$} & $\begin{array}{l}\text { Mean } \pm \\
\text { SEM }\end{array}$ & $\begin{array}{l}98.80 \pm \\
11.26\end{array}$ & $\begin{array}{l}75.71 \pm \\
13.40\end{array}$ & $\begin{array}{l}144.95 \\
\pm 8.55\end{array}$ & $\begin{array}{l}162.74 \\
\pm 16.34\end{array}$ & $\begin{array}{l}137,72 \\
\pm 13.75\end{array}$ & $\begin{array}{l}108.99 \\
\pm 12.13\end{array}$ & $\begin{array}{l}155.81 \\
\pm 23.70\end{array}$ \\
\hline & Minimum & 30.23 & 6.25 & 9.43 & 9.43 & 19.01 & 31.70 & 19.00 \\
\hline & Maximum & 146.24 & 150.98 & 764.47 & 764.47 & 646.10 & 256.00 & 427.00 \\
\hline \multirow[t]{3}{*}{$\begin{array}{l}\text { CSF IgA } \\
\text { (mg/dL) }\end{array}$} & $\begin{array}{l}\text { Mean } \pm \\
\text { SEM }\end{array}$ & $\begin{array}{l}0.123 \pm \\
0.014\end{array}$ & $\begin{array}{l}0.085 \pm \\
0.012\end{array}$ & $\begin{array}{l}0.71 \pm \\
0.60\end{array}$ & $\begin{array}{l}0.11 \pm \\
0.015\end{array}$ & $\begin{array}{l}0.101 \\
\pm 0.014\end{array}$ & $\begin{array}{l}0.070 \\
\pm 0.015\end{array}$ & $\begin{array}{l}4.48 \pm \\
4.28\end{array}$ \\
\hline & Minimum & 0.039 & 0.012 & 0.002 & 0.002 & 0.006 & 0.010 & 0,01 \\
\hline & Maximum & 0.195 & 0.158 & 90.09 & 0.51 & 0.620 & 0.295 & 90.09 \\
\hline $\begin{array}{l}\text { Serum Albumin } \\
\mathrm{g} / \mathrm{L}\end{array}$ & $\begin{array}{l}\text { Mean } \pm \\
\text { SEM }\end{array}$ & $4.15 \pm 0.10$ & $\begin{array}{l}4.05 \pm \\
0.13\end{array}$ & $\begin{array}{l}4.42 \pm \\
0.04\end{array}$ & $\begin{array}{l}4.56 \pm \\
0.06\end{array}$ & $\begin{array}{l}4.47 \pm \\
0.06\end{array}$ & $\begin{array}{l}4.21 \pm \\
0.09\end{array}$ & $\begin{array}{l}4.15 \pm \\
0.09\end{array}$ \\
\hline $\begin{array}{l}\text { CSF Albumin } \\
\mathrm{mg} / \mathrm{L}\end{array}$ & $\begin{array}{l}\text { Mean } \pm \\
\text { SEM }\end{array}$ & $\begin{array}{l}31.97 \pm \\
12.56\end{array}$ & $\begin{array}{l}15.79 .15 \\
\pm 2.06\end{array}$ & $\begin{array}{l}20.68 \\
\pm 0.66\end{array}$ & $\begin{array}{l}19.20 \\
\pm 0.92\end{array}$ & $\begin{array}{l}20.17 \\
\pm 1.03\end{array}$ & $\begin{array}{l}24.79 \\
\pm 2.29\end{array}$ & $\begin{array}{l}21.14 \\
\pm 1.62\end{array}$ \\
\hline \multicolumn{2}{|l|}{$\begin{array}{l}\text { Positive IAS } \\
\text { calculated by } \\
\text { Reiber index }\end{array}$} & $14.30 \%$ & $21,40 \%$ & $14.10 \%$ & $16,10 \%$ & $10.40 \%$ & $12.50 \%$ & $19,00 \%$ \\
\hline \multicolumn{9}{|c|}{$\begin{array}{l}\text { NonMSDND: Non-MS demyelinating neurological diseases. NDND: non-demyelinating neurological diseases. } \\
\text { MS: multiple sclerosis patients. CIS: clinically isolated syndrome; RRMS: relapsing-remiting multiple sclerosis; } \\
\text { SPMS: secondary progressive multiple sclerosis; PPMS: primary progressive multiple sclerosis SEM: standard } \\
\text { error of the mean. IAS: intrathecal IgA synthesis. }\end{array}$} \\
\hline
\end{tabular}

Most of the studied individuals (163/173) showed an IgA concentration in serum within the normal range (70-400 $\mathrm{mg} / \mathrm{dl})^{13}$. Only three MS patients showed a serum IgA concentration above the normal range, who had a normal 
IgA level in the CSF. Low IgA concentration in serum $(<20 \mathrm{mg} / \mathrm{ml})$ was detected in $2 / 22$ individuals from the control group and in 5/151 MS patients, all of them showed a low $\lg A$ concentration in CSF.

However, only $60.11 \%$ of the patients (104/173) showed an IgA concentration in CSF within the range previously described in patients without neurological diseases $(0.06-0.4 \mathrm{mg} / \mathrm{dl})^{12} .5 \mathrm{MS}$ patients showed an $\operatorname{lgA}$ concentration in CSF over normal range, but they had normal IgA concentration in serum. We observed low IgA concentrations in CSF in 6/22 individuals from the control group, and in 58/151 MS patients. From those, only 2 individuals from the control group and $5 \mathrm{MS}$ patients showed a low concentration of serum IgA. No statistically significant differences in IgA concentration were detected neither in CSF nor in serum when MS and control group were compared. Neither did we detect differences among MS patients in different stages of the diseases.

Then, we analyzed the presence of IAS using the Reiber diagram (Table 2). We did not detect statistical significances between MS patients and control group in the percentage of IAS when the Reiber diagram was used. Neither did we detect differences among the different MS types.

\subsection{Detection of OGIgAB by a new isoelectrofocusing and immunodetection assay.}

Once demonstrated the linearity, accuracy, and reproducibility of the new assay (Supplementary Data 2), we studied the sensitivity of the method to detect OGIgAB. The visual analysis of the western blots demonstrated that it was possible to detect OGIgAB when the amount of IgA applied on the gel was $0.5 \mathrm{ng}$ (Fig. 1A). Polyclonal IgA but no OGIgAB were detected when the amount of IgA applied on the gel was $0.25 \mathrm{ng}$. IgA was not detected when the amount of IgA applied on the gel was $0.125 \mathrm{ng}$. In order to validate these results, we quantified the optic density per area (pixels) of the whole range of dilutions (Lanes 1-5). The densitometric analysis also showed that the OGIgAB pattern (peaks a-h) is reproducible and detectable from Lane 1 to 3 . No peaks were observed in lanes 4-5 (Fig. 1B). In addition, the sensitivity of the IEF and immunodetection assay to detect OGIgAB is 5 times higher than the limit of blank (0.095 ng of $\lg A)$ and 2 times higher than the limit of detection $(0.236 \mathrm{ng}$ of $\lg A)$.

Then, we analyzed if the assay was sensitive enough to detect the presence of OGIgAB in all CSF samples. This new assay can detect OGIgAB when the IgA concentration in CSF or serum samples is equal or higher than 0.01 $\mathrm{mg} / \mathrm{dL}$. Taking into account the IgA concentration in our cohort (Table 2) and supposing a Gaussian distribution, the $99.9 \%$ of the population would have a $\operatorname{lgA}$ concentration higher than $0.05 \mathrm{mg} / \mathrm{dL}$ (mean $\pm 3.291 * S E M$ (standard error of the mean)).

Once demonstrated that the new IEF and immunodetection assay could detect up to five times more than required, we analyzed the presence of OGIgAB in samples from MS patients and control group.

Then, we analyzed paired CSF and serum samples from both, control group and MS patients, and we observed four different patterns (Fig. 2):

- Pattern I. Polyclonal IgA in serum and in CSF.

- Pattern II. OGIgAB in serum and the same OGIgAB in CSF.

- Pattern III. OGIgAB in CSF, but not in serum

- Pattern IV. OGIgAB in serum, and two or more additional OGIgAB in CSF. 
The incidence of these patterns is described in Table 3. Then, we grouped the individuals in two categories: patients without (Pattern I and Pattern II) and with (Pattern III and Pattern IV) IAS (Table 3). We detected a higher percentage of IAS in of MS patients $(43.00 \%)$ than in control group $(18.20 \%$; $=0.035)$.

Table 3

Detection of OClgAB in paired CSF and serum samples from MS and control patients.

\begin{tabular}{|lllll|}
\hline & Pattern I & Pattern II & Pattern III & Pattern IV \\
\hline NonMSDND $(n=10)$ & $12.50 \%(1)$ & $75.00 \%(6)$ & $12.50 \%(1)$ & $0.00 \%(0)$ \\
\hline NDND $(n=12)$ & $7.14 \%(1)$ & $71.43 \%(10)$ & $7.1 \%(1)$ & $14.3 \%(2)$ \\
\hline MS $(n=151)$ & $21.90 \%(33)$ & $35.10 \%(53)$ & $12.60 \%(19)$ & $30.50 \%(46)$ \\
\hline CIS $(n=56)$ & $16.10 \%(9)$ & $17.90 \%(10)$ & $19.60 \%(11)$ & $46.40 \%(26)$ \\
\hline RRMS $(n=50)$ & $32.00 \%(16)$ & $34.00 \%(17)$ & $6.00 \%(3)$ & $28.00 \%(14)$ \\
\hline SPMS $(n=24)$ & $20.80 \%(5)$ & $41.7 \%(10)$ & $16.70 \%(24)$ & $20.80 \%(4)$ \\
\hline PPMS ( $n=21)$ & $14.30 \%(3)$ & $76.20 \%(16)$ & $4.80 \%(1)$ & $4.80 \%(1)$ \\
\hline $\begin{array}{l}\text { NonMSDND. Non-MS demyelinating neurological diseases. NDND: non-demyelinating neurological diseases. } \\
\text { MS: } \text { multiple sclerosis. CIS: clinically isolated syndrome; RRMS: relapsing-remiting multiple sclerosis; SPMS: } \\
\text { secondary progressive multiple sclerosis; PPMS: primary progressive multiple sclerosis }\end{array}$ & \\
\hline
\end{tabular}

Then, we studied the specificity of the detection of IAS in MS, which reached $96.30 \%$.

To study in detail the sensibility and specificity of the assay, we analyzed the presence of IAS in individuals with low and high concentration of IgA in CSF.

Only 1/5 MS patients showing high IgA concentrations in CSF had IAS. However, we could detect OGIgAB in 51/62 CSF samples showing low IgA concentration, and 20 of these individuals had IAS. The individuals from the control group showing IAS (4/22) were patients with intracranial hypertension, Non-Hodgkin lymphoma, epilepsy, and myelitis.

\subsection{Presence of IAS in the different phases of the disease}

We also aimed to analyze the relation IAS and the progression of the disease. CIS patients showed a significant higher percentage of IAS (66.00\%) than RRMS (34.00\%; $p=0.002)$, SPMS (37.50\%; $p=0.026)$; PPMS $(9.50 \%$; $p<$ $0.0001)$ and control subgroups NonMSDND (12.50\%; $p=0.006)$ and NDND $(21.40 \% ; p=0.005)$. PPMS also showed a lower IAS percentage than RRMS ( $p=0.041)$ and SPMS $(p=0.040)$. No differences were detected when RRMS, SPMS, PP patients and control subgroups were compared (Fig. 3).

\section{Discussion}

There are not many reports about the contribution of IgA in MS patients, because its detection is cumbersome ${ }^{12}$. It was reported that qualitative methods are the most sensitive methods to detect intrathecal immunoglobulin synthesis ${ }^{7}$. For these reasons, we aimed to develop a new method based on IEF and immunodetection to detect OGIgAB in CSF and serum samples to analyze the presence of IAS in MS patients. 
First, we developed a high sensitive quantitative ELISA to analyze the IgA concentration in CSF and serum samples. Once demonstrated the linearity, accuracy, sensibility and reproducibility of the ELISA, we analyzed the concentration of this immunoglobulin in samples from patients with MS and different neurological diseases.

In our cohort, IgA concentration in serum samples was found within normal ranges in most cases. The analysis of CSF showed an IgA concentration within the previously described normal range ${ }^{12}$ in most case but a considerable number of the individuals (37.00\%) had a low IgA concentration, which make difficult to detect IAS. We did not detect significant differences in the IgA concentration between patients with MS or different neurological diseases, neither in CSF nor in serum samples. Neither did we detect statistical differences when the different MS types were compared.

Then we analyzed the presence of IAS by a quantitative method, the Reiber diagram, and we observed that the percentage of MS patients showing IAS using this method was similar to described previously ${ }^{7}$. Using this method the percentage of IAS were similar in MS patients and control group.

Then we developed a new high IEF and immunodetection to detect OGIgAB in order to study the presence of IAS in MS patients and control group. We overcame the difficulties associated with the analysis of this immunoglobulin by qualitative methods as follows. First, as it was described that the proportion of dimeric IgA increases from 5\%, up to $53.9 \%$ when control and MS patients are compared ${ }^{14}$, samples were reduced using DTT to obtain monomeric $\lg \mathrm{A}$. Second, to avoid the IgA precipitation we employed agarose instead of acrylamide gels ${ }^{12}$. Third, to detect IgA at low concentration in CSF, biotin-streptavidin amplification method was used. Finally, we employed alkaline phosphatase to develop the staining, this enzyme improves 10 fold the sensitivity of the assay compared with peroxidase $^{1}$.

Once established the best conditions, we demonstrated the linearity, accuracy and reproducibility of the IEF and immunodetection. The sensitive of this new IEF technique, higher than methods used previously ${ }^{8}$, was enough to identify OGIgAB in all samples in our cohort, despite of the high percentage of individuals with a low $\lg A$ concentration in CSF. This immunoassay showed four different patterns. Pattern I (polyclonal IgA in CSF and serum) indicates that all the B-lymphocytes release a limited amount of antibody because they are not stimulated, this is the normal situation. Pattern II (the same OGIgAB in CSF and serum) involves activated peripheral Blymphocytes producing this immunoglobulin, which finally passes through the brain blood barrier to the CNS. Pattern III (presence of OGIgAB in CSF but not in serum) demonstrates the presence of B-lymphocytes releasing this immunoglobulin in the CNS. Pattern IV (two or more OGIgAB in CSF compared with serum) discloses the presence of activated B-lymphocytes in the CNS, but also indicates that some are also activated in the peripheral system.

According to these patterns, we could identify IAS in a higher percentage than described before for MS patients ${ }^{14}$. This new assay is more sensitive than Reibergram to detect IAS, corroborating that qualitative techniques are more sensitive than quantitative methods ${ }^{6,15}$. IAS was not related with IgA concentration in CSF, because we detected it in individuals with a low IgA concentration, but we did not in patients showing high levels.

IAS is highly specific of MS patients, because its incidence is higher in these individuals than in those form the control groups, despite of the inclusion of inflammatory diseases of the central nervous system as controls. Most of the MS patients with IAS showed Pattern IV, in contrast to the situation observed when IgG or IgM oligoclonal bands are analyzed ${ }^{1,16}$. Therefore, the presence of additional oligoclonal bands in CSF is the most frequent 
pattern. Nevertheless, a considerable percentage of MS patients showed Pattern II. This was not expected, because this pattern is not usually observed when $\lg G$ or $\operatorname{lgM}$ oligoclonal bands are analyzed in MS patients ${ }^{1,16}$.

Interestingly, the higher percentage of IAS was observed in CIS patients. The incidence of Pattern II was particularly high in NonMSDND (75,00\%) and NDND (71.43\%) patients, indicating again a specific difference of IgA-bands distribution in MS patients. This also could indicate that origin of the lymphocyte activation is different depending on the disease.

All these data suggest that $\lg \mathrm{A}$, as the other immunoglobulins, could have a dual role in MS, protecting against the disease or promoting the cell damage.

Regarding the protective role of $\lg \mathrm{A}$ in MS, it was recently described that recirculating intestinal IgA positive cells prevent the development of experimental autoimmune encephalomyelitis, the animal model of MS, because they release IL-10 ${ }^{17}$. We have described above the high incidence of OCIgAB in serum samples from the MS group, demonstrating the usual presence of peripheral activated $B$ lymphocytes in these individuals.

Moreover, it is involved in the first line of defense against pathogens, and the presence of virus in MS patients has been broadly demonstrated, for example, our group has previously detected human herpesvirus 6 , JC virus and Epstein Barr virus in the CSF and central nervous system of these MS patients ${ }^{11,18,19}$. In addition, viruses were also found in the CSF at the first demyelinated event ${ }^{19}$, and it was demonstrated that infections increase the risk of relapses ${ }^{20}$. Regarding this, we observed a high incidence of IAS in CIS patients but a lower incidence in RRMS, SPMS and PPMS.

On the other hand, antibodies contribute to eliminate cells infected by viruses, because they promote antibodydependent cellular cytotoxicity ${ }^{21}$. Moreover, the activation of the immune system could trigger cross-reactions against self-antigens, one of the classical hypothesis in autoimmunity ${ }^{22}$. IgA deposits observed in demyelinated areas of MS patients are related with axonal damage ${ }^{9}$.

In summary, here we present a highly sensitive technique to detect OGIgAB in CSF and serum samples. Our findings draw attention to the high prevalence of IAS in MS patients, especially in CIS group. Further studies would be of great interest to clarify the role of this immunoglobulin in the physiopathology of MS.

\section{Declarations}

\section{Declarations}

DISCLOSURE

OF CONFLICTS OF INTEREST

\section{AUTHOR CONTRIBUTION}

U.M: Performed experiments, analyzed results and wrote the manuscript

\section{ACKNOWLEDGMENTS}


This work was supported by grants: USP-BS-PPC16/2012, PCON11/2016 and PI14/01620 from Banco SantanderUniversidad San Pablo; MEMERG-1 from IMMA, Universidad San Pablo CEU; PI16/01259 and PI15/00821 from Instituto de Salud Carlos III. We want to particularly acknowledge the patients and the Biobanco del Sistema Sanitario Público de Andalucía (Nodo HU Virgen Macarena) (PT20/00069) integrated in the Spanish National Biobanks Network and supported by Instituto de Salud Carlos III-FEDER for its collaboration.

\section{References}

1. Sádaba, M. C. et al. An ultrasensitive method for the detection of oligoclonal IgG bands. J Immunol Methods, 284, 141-145 https://doi.org/10.1016/j.jim.2003.09.018 (2004).

2. Poser, C. M. et al. New diagnostic criteria for multiple sclerosis: guidelines for research protocols. Ann Neurol, 13, 227-231 https://doi.org/10.1002/ana.410130302 (1983).

3. Villar, L. M. et al. Early differential diagnosis of multiple sclerosis using a new oligoclonal band test. Arch Neurol, 62, 574-577 https://doi.org/10.1001/archneur.62.4.574 (2005).

4. Villar, L. M. et al. Intrathecal IgM synthesis in neurologic diseases: relationship with disability in MS. Neurology, 58, 824-826 (2002).

5. Villar, L. M. et al. Intrathecal synthesis of oligoclonal IgM against myelin lipids predicts an aggressive disease course in MS. J Clin Invest, 115, 187-194 https://doi.org/10.1172/JCl22833 (2005).

6. McLean, B. N., Luxton, R. W. \& Thompson, E. J. A study of immunoglobulin G in the cerebrospinal fluid of 1007 patients with suspected neurological disease using isoelectric focusing and the Log IgG-Index. A comparison and diagnostic applications., 113 (Pt 5), 1269-1289 (1990).

7. Reiber, H. \& Peter, J. B. Cerebrospinal fluid analysis: disease-related data patterns and evaluation programs. $J$ Neurol Sci, 184, 101-122 (2001).

8. Kaiser, R. \& Lücking, C. H. Intrathecal synthesis of IgM and IgA in neurological diseases: comparison of two formulae with isoelectric focusing. Clin Chim Acta, 216, 39-51 (1993).

9. Zhang, Y. et al. Clonal expansion of IgA-positive plasma cells and axon-reactive antibodies in MS lesions. $J$ Neuroimmunol, 167, 120-130 https://doi.org/10.1016/j.jneuroim.2005.05.006 (2005).

10. Mussini, J. M., Hauw, J. J., Delasnerie, N., Schuller, E. \& Escourolle, R. Intracytoplasmic immunoglobulinbinding lymphoid cells (IgGLC) of the cerebrospinal fluid in multiple sclerosis and other neurological disorders. Ann Immunol (Paris), 131C, 55-67 (1980).

11. Tzartos, J. S. et al. Association of innate immune activation with latent Epstein-Barr virus in active MS lesions. Neurology, 78, 15-23 https://doi.org/10.1212/WNL.0b013e31823ed057 (2012).

12. Withold, W., Wick, M., Fateh-Moghadam, A. \& Einhäupl, K. Detection of oligoclonal IgA in cerebrospinal fluid samples by an isoelectric focusing procedure. J Neurol, 241, 315-319 (1994).

13. Gonzalez-Quintela, A. et al. Serum levels of immunoglobulins (lgG, $\lg A$, $\lg M)$ in a general adult population and their relationship with alcohol consumption, smoking and common metabolic abnormalities. Clin Exp Immunol, 151, 42-50 https://doi.org/10.1111/j.1365-2249.2007.03545.x (2008).

14. Sindic, C. J., Delacroix, D. L., Vaerman, J. P., Laterre, E. C. \& Masson, P. L. Study of IgA in the cerebrospinal fluid of neurological patients with special reference to size, subclass and local production. J Neuroimmunol, 7, 6575 (1984). 
15. Luxton, R. W., McLean, B. N. \& Thompson, E. J. Isoelectric focusing versus quantitative measurements in the detection of intrathecal local synthesis of IgG. Clin Chim Acta, 187, 297-308 https://doi.org/10.1016/00098981(90)90115-9 (1990).

16. Villar, L. M. et al. A sensitive and reproducible method for the detection of oligoclonal IgM bands. J Immunol Methods, 258, 151-155 (2001).

17. Rojas, O. L. et al. Recirculating Intestinal IgA-Producing Cells Regulate Neuroinflammation via IL-10., 176, 610624618 https://doi.org/10.1016/j.cell.2018.11.035 (2019).

18. Alvarez-Lafuente, R. et al. Herpesviruses and human endogenous retroviral sequences in the cerebrospinal fluid of multiple sclerosis patients. Mult Scler, 14, 595-601 https://doi.org/10.1177/1352458507086425 (2008).

19. Alvarez-Lafuente, R., García-Montojo, M., De Las Heras, V., Bartolomé, M. \& Arroyo, R. JC virus in cerebrospinal fluid samples of multiple sclerosis patients at the first demyelinating event. Mult Scler, 13, 590-595 https://doi.org/10.1177/1352458506073116 (2007).

20. Buljevac, D. et al. Prospective study on the relationship between infections and multiple sclerosis exacerbations., 125, 952-960 (2002).

21. Ye, Z. W. et al. Antibody-Dependent Cell-Mediated Cytotoxicity Epitopes on the Hemagglutinin Head Region of Pandemic H1N1 Influenza Virus Play Detrimental Roles in H1N1-Infected Mice. Front Immunol, 8, 317 https://doi.org/10.3389/fimmu.2017.00317 (2017).

22. Albert, L. J. \& Inman, R. D. Molecular mimicry and autoimmunity. N Engl J Med, 341, 2068-2074 https://doi.org/10.1056/NEJM199912303412707 (1999).

\section{Figures}


Fig. 1
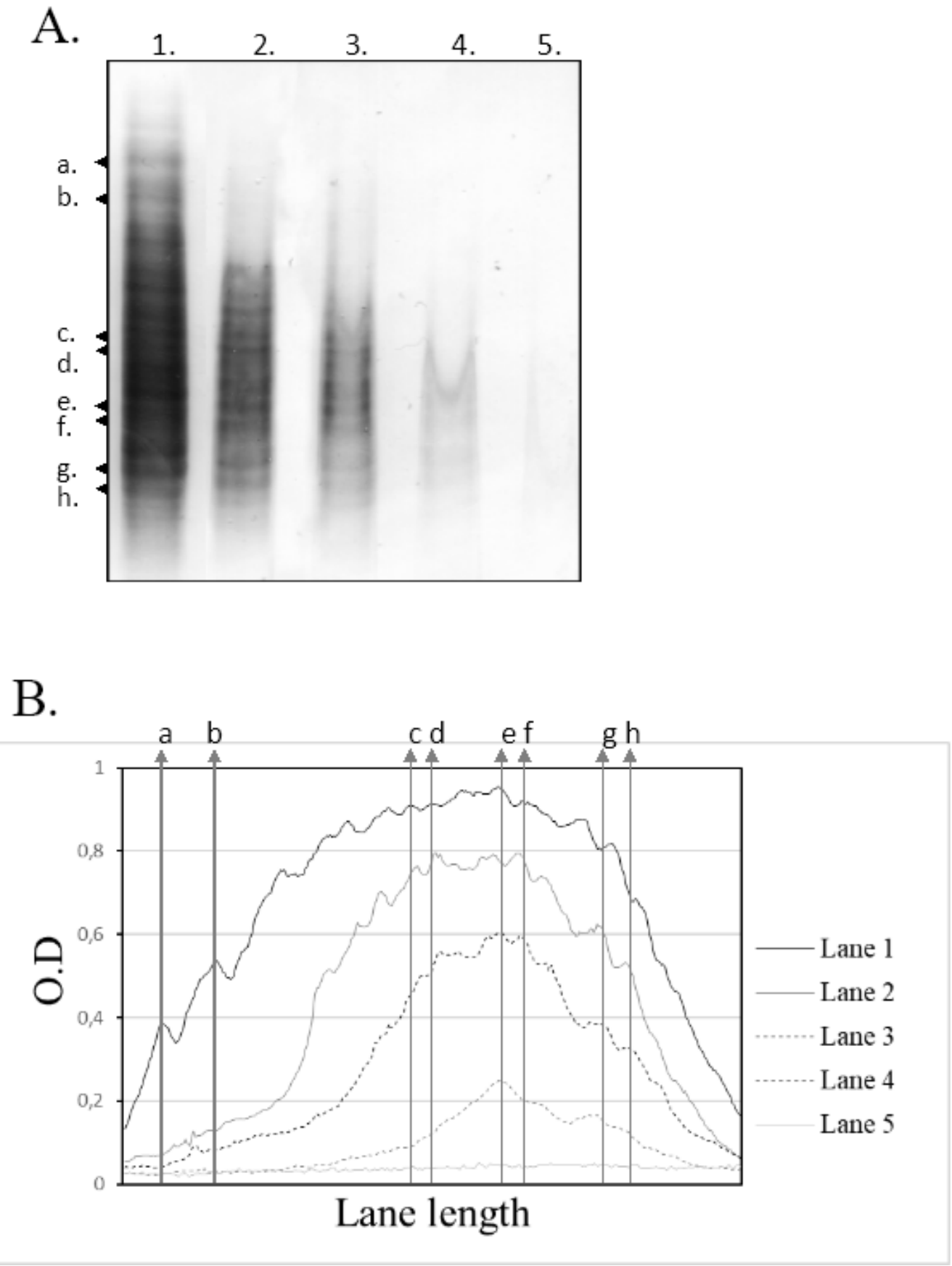

\section{Figure 1}

IEF and immunodetection of OCIgAB in a diluted serum sample from a MS patient. The quantity of IgA in lines 1-5 was: 4, 2, 1, 0.5 and 0.25 ng, respectively. A) OClgAB were observed in lines 1-4. but not in line 5. B) The densitometric analysis of the band pattern in lines 1-4 showed a similar and reproducible OClgAB pattern in all the lanes quantified. Arrows show specific bands (A) and its corresponding densitometric signals in the linescan analysis (B). Note that a single band corresponds to a density peak in the linescan analysis in most of the lanes. O.D is represented as relative O.D, the value obtained divided by maximum. 
Fig. 2

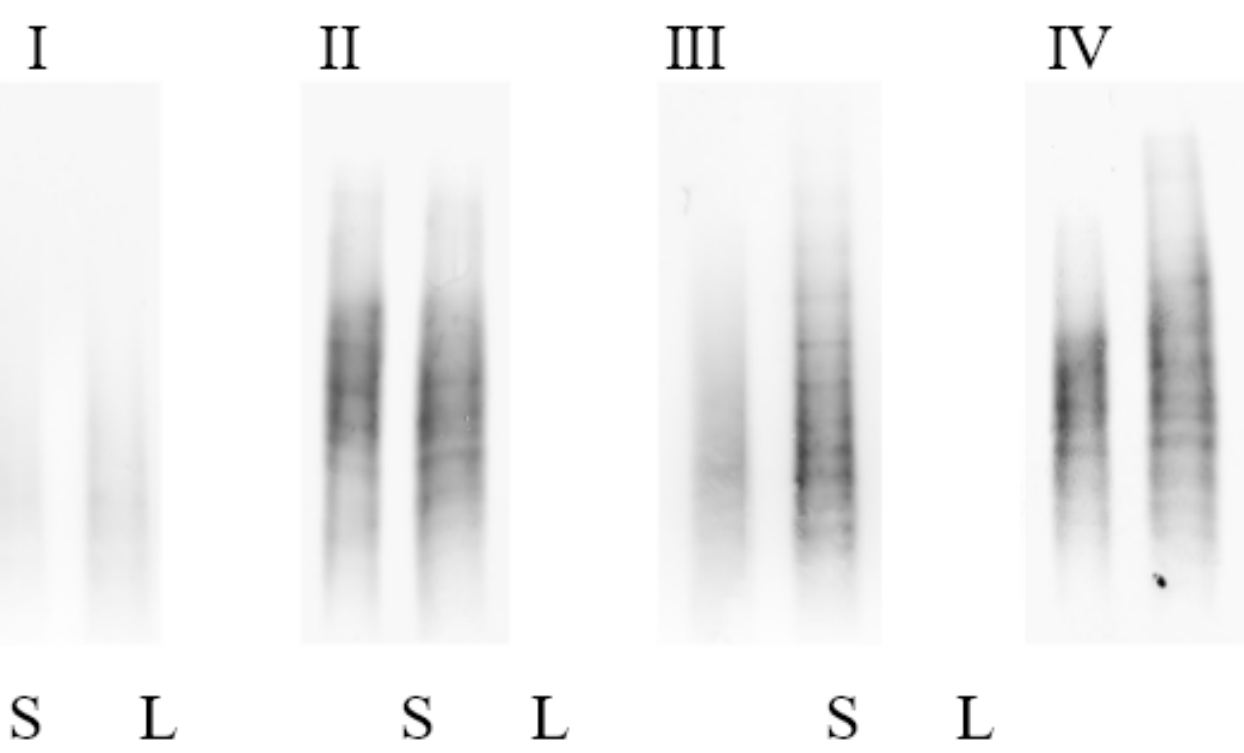

Figure 2

Detection of OClgAB in paired CSF and serum samples from 4 MS patients. Representative blottings of individuals showing Pattern 1 (I), Pattern 2 (II), Pattern 3 (III) and Pattern 4 (IV). S: serum. L: cerebrospinal fluid. 
Fig.3.

$\mathrm{p}=0.005$

$p=0.006$

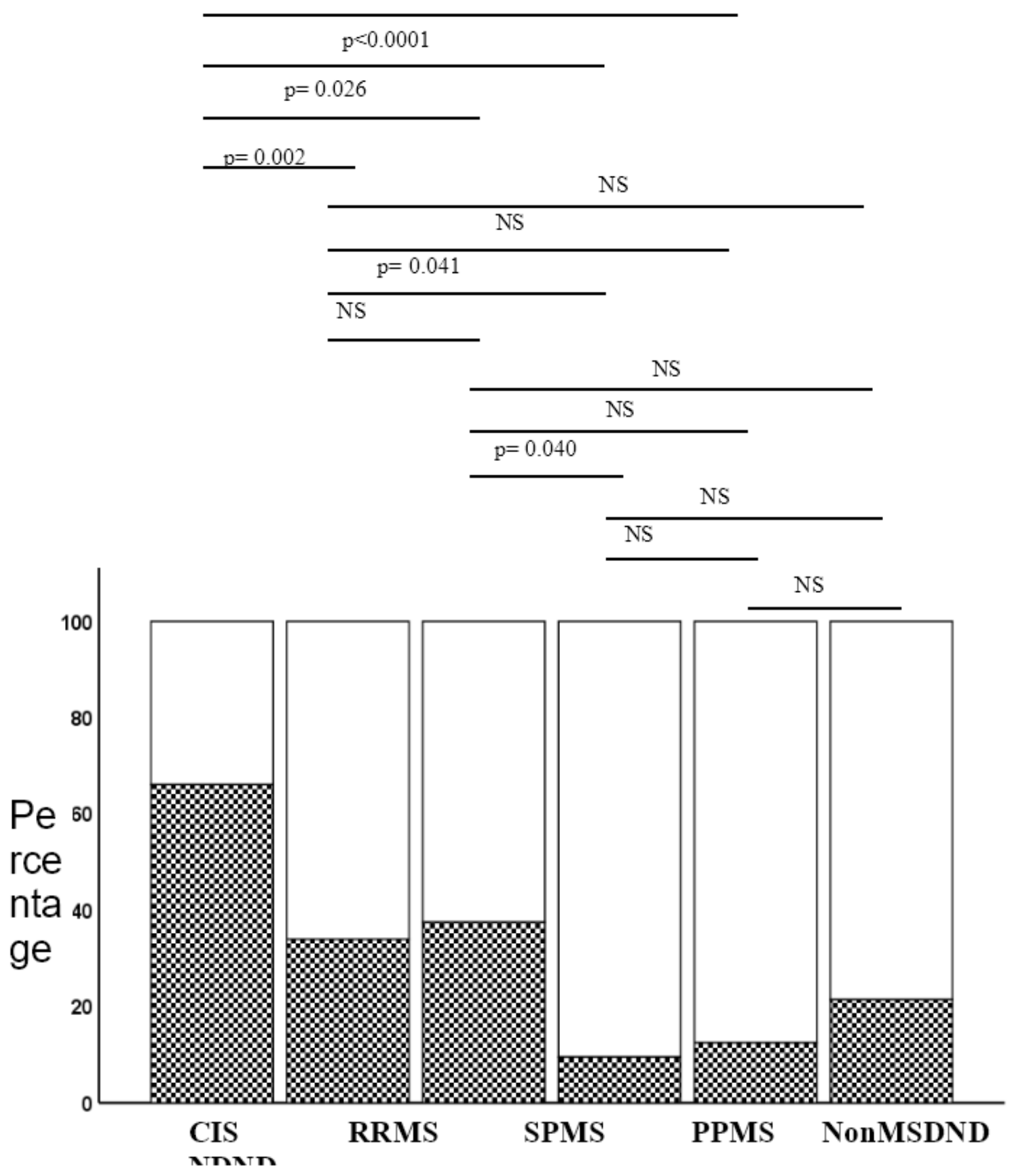

Figure 3

Study of the percentage of intrathecal IgA synthesis in MS groups. White area represent the percentage of individuals of each group without IAS. Squared areas represent the percentage of individuals with IAS. CIS: clinically isolated syndrome. RRMS: relapsing-remitting patients.

\section{Supplementary Files}

This is a list of supplementary files associated with this preprint. Click to download.

- SuplementaryData.S.R.odt 